\title{
OPEN 3D morphology of nematode encapsulation in snail shells, revealed by micro-CT imaging
}

\author{
P. Falkingham \& R. Rae ${ }^{凶}$
}

Many parasites and hosts are embroiled in an on-going arms race that affects the evolution of each participant. One such battle is between parasitic nematodes and terrestrial gastropods which have co-evolved for 90-130 MY. Recently, snails have been shown to encase and kill invading nematodes using their shell as a defence mechanism. However, there is remarkably little known about this process in terms of understanding where, when and how nematodes are fixed within the shell. Also there has never been any attempt to observe this process using methods other than light microscopy. Therefore, we used micro CT scanning of a Cepaea nemoralis shell (a common host for nematodes) to 3D visualise encased nematode parasites and quantify morphological parameters. By taking this approach future studies could use micro CT scanning of fossil shells in conchology collections to understand nematode/ snail co-evolution.

The co-evolutionary arms race between host and parasite has resulted in rapid changes in the evolution of the immune system ${ }^{1}$. Terrestrial gastropods (slugs and snails) are parasitised regularly by flies, protozoa, trematodes and viruses ${ }^{2}$, but nematodes are the most prolific parasites with 108 species (representing four out of five clades of the Nematoda) using terrestrial gastropods as definitive, intermediate and paratenic hosts ${ }^{3-5}$. This arms race has been on going for 90-130 $\mathrm{MY}^{6}$. Examples include Caenorhabditis elegans Maupas which is thought to use slugs and snails for transport ${ }^{7}$ and Angiostrongylus vasorum Baillet (the casual agent of cardio/pulmonary disease in dogs) uses snails as intermediate hosts to facilitate transmission to mammals ${ }^{8}$. In order to combat parasites, terrestrial gastropods use Reactive Oxygen Species (ROS), antimicrobial peptides and lectins to kill invading parasites ${ }^{9}$, but in general, their immune system is poorly researched ${ }^{10}$. Interestingly, recent studies examining the susceptibility of snails to the commercially available biological control agent nematode parasite Phasmarhabditis hermaphrodita Schneider (sold as Nemaslug) ${ }^{11}$, observed nematodes being trapped, encased and killed by unknown cells fusing the animals to the inner part of the shell en masse $\mathrm{e}^{12-16}$. The shell is made of an outer proteinaceous periostracum of conchiolin and crystalline calcium carbonate sub-layers ${ }^{17}$ and is used for shelter from extreme environmental conditions but this recent research posits the shell has been co-opted to kill nematodes ${ }^{14}$. Upon nematode infection, cells on the shell surface aggregate and adhere to the nematode cuticle and fuse it to the inner shell, often hundreds at a time. This was initially observed in infection experiments with the giant African snail (Lissachatina fulica) Férussac ${ }^{12}$ and has subsequently been observed in live Cepaea nemoralis L. ${ }^{13}$, Arianta arbustorum L. ${ }^{15}$ and in museum collections of Cornu aspersum Müller ${ }^{16}$ and across many representatives of the Stylommatophora ${ }^{14}$, even in the vestigial shell of slugs ${ }^{18}$. By examining shells in conchology collections nematodes over 500 years old have been observed ${ }^{14}$. This in vivo fossilisation process could allow an unprecedented insight into spatial and temporal changes in co-evolutionary dynamics between nematodes and snails. Also as nematode DNA can be extracted from preserved shells to aid identification to species $^{14,16}$ the molecular evolution of nematodes could be tracked over time. As nematodes are soft bodied and do not fossilise $\mathrm{e}^{19,20}$ this approach has huge potential however, the basic processes involved in encapsulation used to kill nematodes are poorly understood. This is primarily as the inner aperture and whorl of a snail's shell is difficult to observe. Light microscopy has been used to view nematodes fixed and fused in shells (Fig. 1) but there have been no other techniques used to investigate this further. Hence, new, non-destructive approaches are needed. One such approach is micro computed tomography (micro CT scanning) that has been successfully used understand the structure of arachnids ${ }^{21}$ and ammonites ${ }^{22}$. Thus, we had two main aims; first, to use micro CT scanning to discover if nematodes can be viewed in the snails' shell and second, whether any morphometric data can be gleaned from such an approach. 


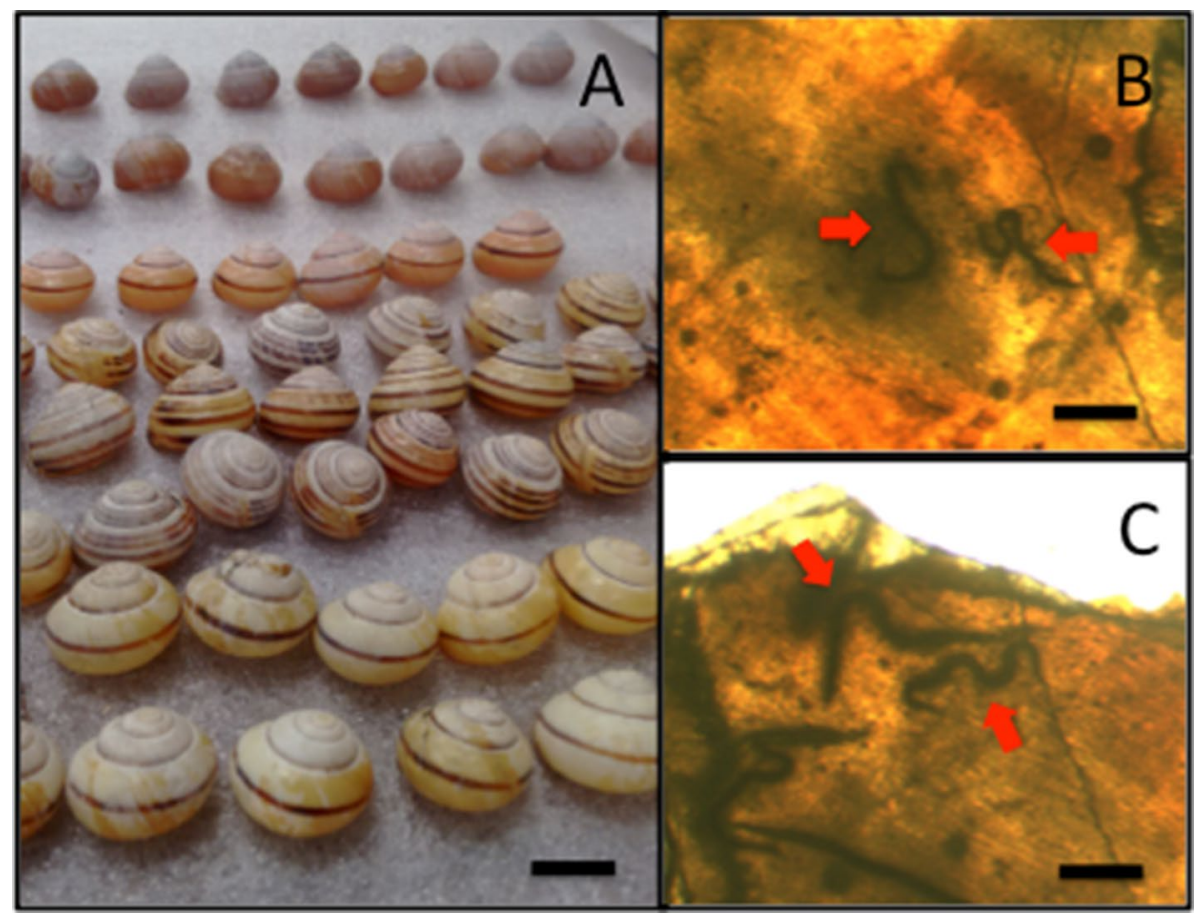

Figure 1. (A) Snails, such as C. nemoralis, regularly encase and kill nematodes in the inner whorl of their shell. The nematodes can be seen by using light microscopy and are fused to the inner shell $(\mathbf{B}, \mathbf{C})$. Bars represent $1 \mathrm{~cm}$ in $(\mathbf{A})$ and $0.5 \mathrm{~mm}$ in $(\mathbf{B}, \mathbf{C})$.

\section{Materials and methods}

Observation and scanning of nematodes encased in snail shells. A collection of approximately 1-2 year old C. nemoralis shells collected from sand dunes in Formby, Sefton $(n=50)$ (Grid Reference: SD273075) were examined for nematodes encased in the inner lip and whorl of the shells using light microscopy following standard procedures ${ }^{12-16}$. One C. nemoralis shell had a prominent nematode fixed opposite the inner whorl of the shell and was used for subsequent studies. The specimens were scanned using a SkyScan 1272, at voxel size of $19.82 \mu \mathrm{m}^{3}$. Voltage and Current were set to $50 \mathrm{kV}$ and $200 \mu \mathrm{A}$ respectively. CT data were analysed using Dragonfly software, version 4 for Windows (http://www.theobjects.com/dragonfly/, Object Research Systems (ORS) Inc, Montreal, Canada). Thresholding was used to isolate shell material in 3D and 2D views, and the encapsulated nematode located. 3D views of the encapsulated nematode were rendered with a "hard gradient" to illustrate the morphology of the feature. $2 \mathrm{D}$ slices detailing the internal morphology of the encapsulation were produced with a rainbow colour map to indicate density (warmer colours indicate higher density). Tomographic data are provided in supplemental data.

\section{Results}

Prior to scanning, one C. nemoralis shell was identified through light microscopy as exhibiting encapsulation of an individual nematode located inside the dorsal portion of the shell (Fig. 2a; Supplementary Video S1). The feature is C-shaped, curving and tapering at both ends. The encapsulation is $\sim 1 \mathrm{~mm}$ long and $0.2 \mathrm{~mm}$ in width, (Fig. 2b,c) and is raised $0.1 \mathrm{~mm}$ above the surrounding shell surface (Fig. 3). The outermost layer of the encapsulation is extremely thin, only a few voxels in width. The interior of the encapsulation is approximately $80 \mu \mathrm{m}$ in width, and has higher density than the surrounding air, but lower density than the shell around it. It is clear there is a cavity produced when the nematode is covered in unknown cells (Fig. 3c). However, the lack of resolution here makes it difficult to draw firm conclusions regarding the nature of the interior of the encapsulation (see Fig. 3c).

\section{Discussion}

The number of shells found with nematodes present was surprisingly low in our study. This is unusual. The number of shells positive for nematode encapsulation as well as the number of nematodes found per shell has been found to be high in field based studies. For example, from C. nemoralis collected from Merseyside, $4-60 \%$ of shells had nematodes present ranging from 1 to 152 nematodes per shell ${ }^{14}$. Similarly, 2-25\% of C. hortensis shells from north Scotland had from 1 to 51 nematodes present ${ }^{14}$. This high infection load is not restricted to snails from the genus Cepaea. All shells of C. aspersum $(\mathrm{n}=136)$ from an escargot farm in northern Ireland had nematodes present in their shells with a mean of $31 \pm 2$ nematodes per shell ${ }^{14,16}$. Snail shells hundreds of years old housed in conchology collections have nematodes encased in their shells. For example, A. arbustorum from $1908^{15}, C$. aspersum and Helix pomatia L. from 1901 and $1904^{16}$ respectively, as well as C. nemoralis from 1864 and even 
A
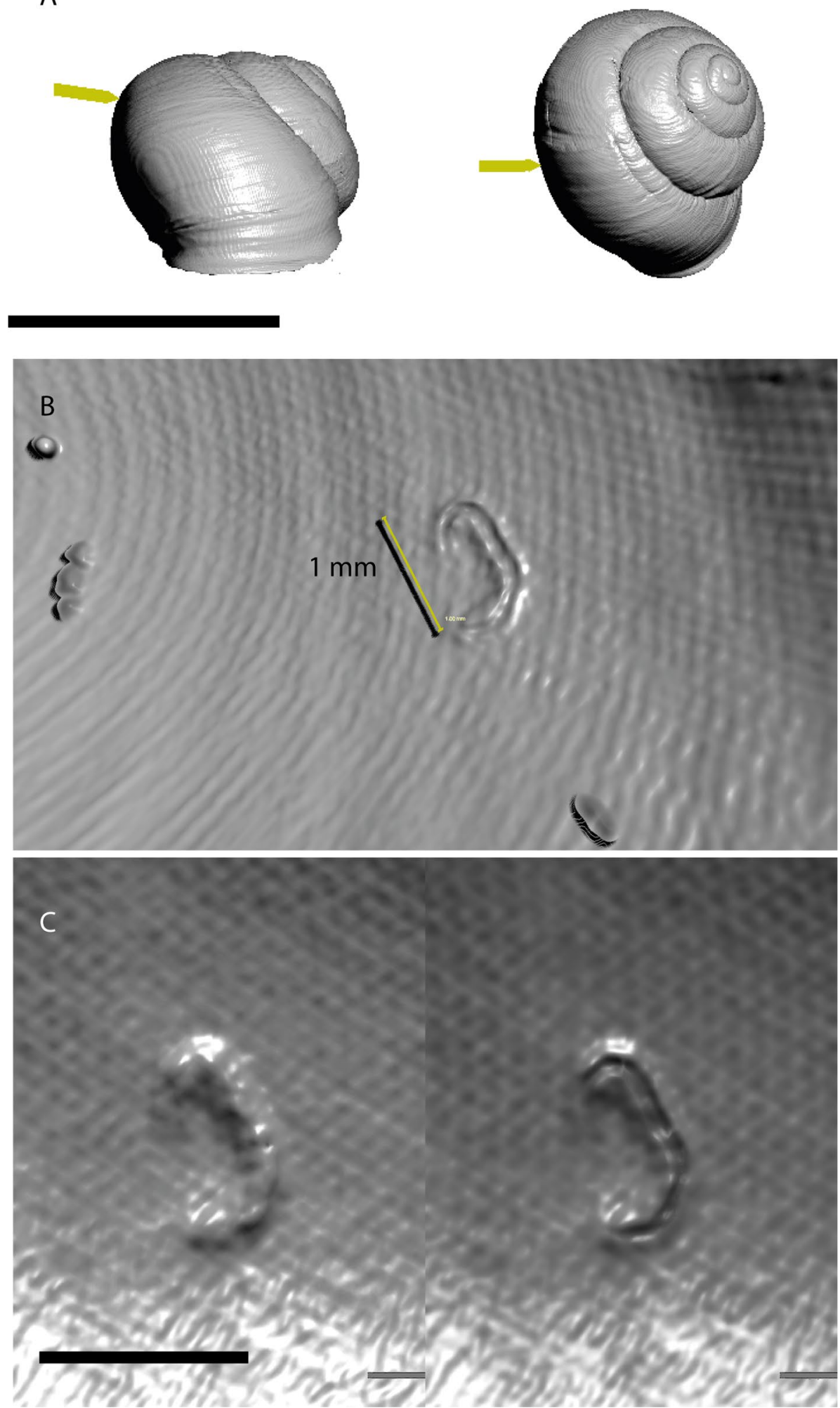

Figure 2. 3D views of the nematode encapsulation. (A) Arrows indicate location of the encapsulation in anterior and dorsal views of the shell. (B) The encapsulation inside the shell. Fine sand grains are also adhered to the inside of the shell and are visible. (C) 3D view of the encapsulation at two slightly different thresholds-on the left, a broader threshold window showing the complete nature of the encapsulation, and right, a narrower thresholding window exposing the internal geometry of the encapsulation. Scale bar $=20 \mathrm{~mm}$ in (A), and $1 \mathrm{~mm}$ in $(\mathbf{B}, \mathbf{C})$. 
A

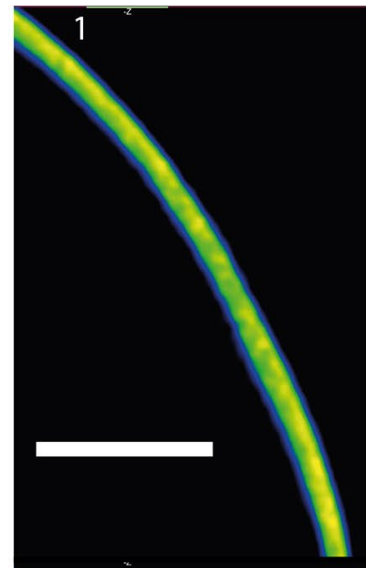

2

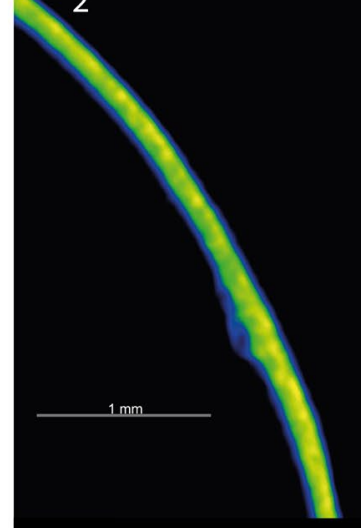

3

\section{4}

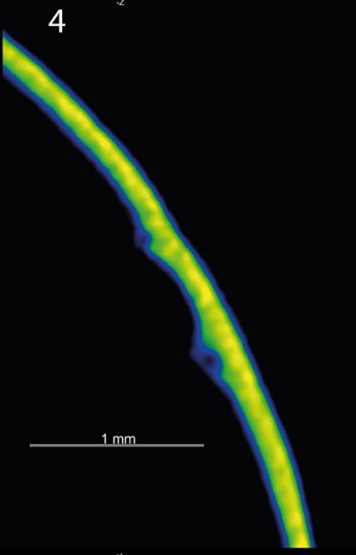

5

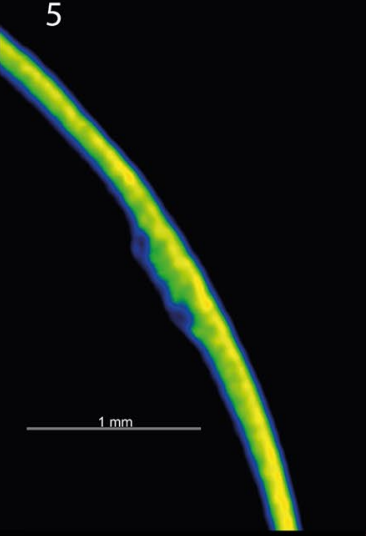

6
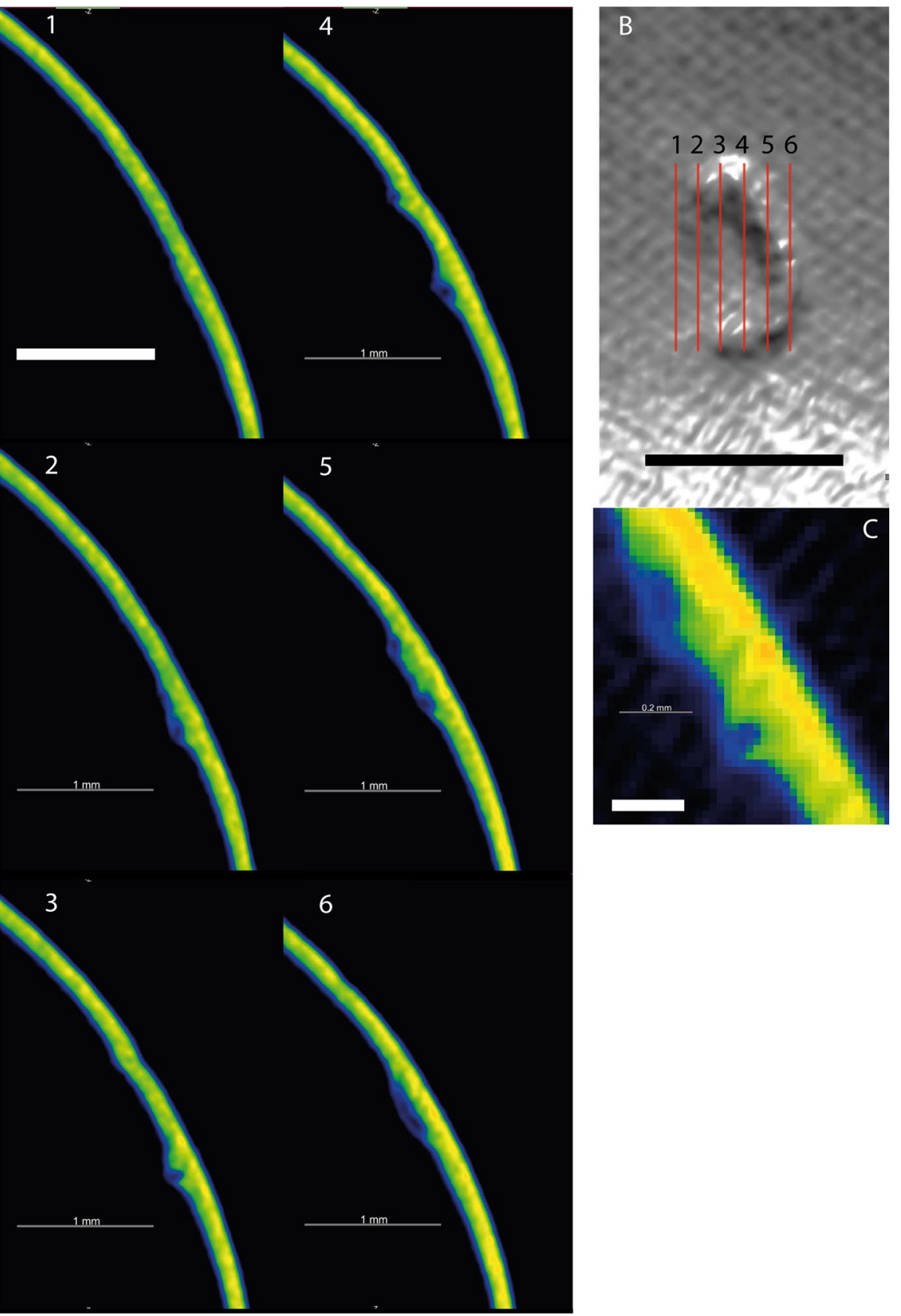

Figure 3. (A) Six sequential slices through the encapsulation and surrounding shell. The complete encapsulation, and tubular nature of the structure can be seen in slices 2-6. Slices are coloured according to density-warmer colours indicate higher density. Slice locations are shown in the upper right (B). (C) Close up slice shown as raw pixel data (non-interpolated). Scale bar in $A+B=1 \mathrm{~mm}$, scale bar in $C=0.2 \mathrm{~mm}$.

over 500 years old ${ }^{14}$ all had nematodes encased in their shells. Therefore, as nematode encapsulation is common in many members of the Stylommatophora ${ }^{14}$ there is ample opportunity for studying the spatial and temporal changes in nematode infection in many different species and locations using light microscopy and $\mu \mathrm{CT}$ scanning.

Previous attempts using standard light microscopy have been able to quantify nematode numbers fixed in snail shells ${ }^{12-16}$ but $3 \mathrm{D}$ visualisation and measurements of individual animals have not been possible. Using micro CT scanning we have been able to remedy this problem. The $1 \mathrm{~mm}$ long nematode fused to the inner shell of $C$. nemoralis was covered with a thin layer of unknown snail cells leaving a clear cavity where the nematode degrades. It was previously unknown whether snail cells would fill this void or if layers were produced on top of the lesion during the encapsulation process. This is an interesting and important discovery for future research, as this cavity will protect nematode DNA from agents responsible for degradation e.g. extreme temperatures and water ${ }^{23}$. Molecular analyses of museum collections have yielded fascinating insights into the evolution of many organism including humans ${ }^{24}$, plants ${ }^{25}$ and even bacterial pathogens ${ }^{26}$. Perhaps this system could be no different. 
If shells are stored correctly in conchology collections this encapsulation process could allow molecular analysis of nematodes over time using fossilised shells. In general, molecular approaches of preserved nematodes have been restricted to genotyping of helminth eggs from coprolites and archaeological digs hundreds even thousands of years old. For example, Ascaris eggs were extracted from coprolites from the Middle-Ages in Belgium ${ }^{27}$ and Ascaris sp. and Trichuris sp. eggs have been identified from environmental samples from Viking age sediment (dated 1018-1030 AD) ${ }^{28}$. This is due to helminth eggs being resistant to environmental stressors. From our understanding there have been no molecular analyses (other than a few genes for genotyping) of preserved nematodes at any other developmental stage as they do not fossilise. In contrast, adult stage nematodes encased in C. nemoralis shells over 500 years old have been observed ${ }^{14}$. Examination of older shells is possible and is highly likely to yield positive shells with evidence of nematode parasitism. One such group of snails to focus on could be edible land snails (e.g. C. aspersum), reared by humans in the late Pleistocene and Holocene and are often abundant in archeological deposits and hence museums ${ }^{29}$. Analysis of these shells could potentially tell us about the evolutionary history of nematodes infecting humans. For example, a common parasite of snails is Angiostrongylus cantonensis Chen the causal agent of human eosinophilic meningoencephalitis worldwide ${ }^{30}$.

Although our study using micro CT scanning was successful in providing information about nematode parasitism of snail shells there are a wealth of techniques to use in future studies including using higher resolution scanners or microscopy including Transmission Election Microscopy (TEM). Scanning Electron Microscopy (SEM) is another possibility though this would involve breaking shells to reveal the nematodes inside.

Providing these 3D observations opens up the opportunity of examining the fossil record for nematodesnail relationships, and exploring the evolution of this defence mechanism. The three dimensional nature of encapsulations like this makes it a very real possibility encapsulated nematodes might be observed in fossil snail specimens via $\mu \mathrm{CT}$ imaging. Armed with this search image, fossil snail collections stretching back hundreds of millions of years may hold important information on when this capability evolved, and how it might be spread across the snail phylogeny.

Received: 30 April 2020; Accepted: 25 November 2020

Published online: 28 January 2021

\section{References}

1. Frank, S. A. Immunology and Evolution of Infectious Diseases (Princeton, Princeton University Press, 2002).

2. Barker, G. M. Natural Enemies of Terrestrial Molluscs (CABI Publishing, Wallingford, 2004).

3. Grewal, P. S., Grewal, S. K., Tan, L. \& Adams, B. J. Parasitism of molluscs by nematodes: types of associations and evolutionary trends. J. Nematol. 35, 146-156 (2003).

4. Blaxter, M. L. et al. A molecular evolutionary framework for the phylum Nematoda. Nature 392, 71-75 (1998).

5. Pieterse, A., Malan, A. P. \& Ross, J. L. Nematodes that associate with terrestrial molluscs as definitive hosts, including Phasmarhabditis hermaphrodita (Rhabditida: Rhabditidae) and its development as a biological molluscicide. J. Helminthol. 91, 517-527 (2017).

6. Tillier, S., Masselot, M. \& Tillier, A. Phylogenic relationships of the pulmonate gastropods from rRNA sequences, and tempo and age of the Stylommatophoran radiation. In Origin and Evolutionary Radiation of the Mollusca (ed. Taylor, J.D.) 267-284 (Oxford, Oxford University Press, 1996).

7. Félix, M-A. \& Braendle, C. The natural history of Caenorhabditis elegans. Curr. Biol. 20, R965-R969 (2010).

8. Bolt, G., Monrad, J., Koch, J. \& Jensen, A. L. Canine angiostrongylosis: a review. Vet. Rec. 135, 447-452 (1994).

9. Loker E.S. Gastropod immunobiology in Invertebrate Immunity (ed. Soderhall, K.) 17-43 (Springer, 2010).

10. South, A. Terrestrial Slugs: Biology, Ecology and Control (Chapman \& Hall, London, 1992).

11. Wilson, M. J., Glen, D. M. \& George, S. K. The rhabditid nematode Phasmarhabditis hermaphrodita as a potential biological control agent for slugs. Biocontrol Sci. Technol. 3, 503-511 (1993).

12. Williams, A. J. \& Rae, R. Susceptibility of the Giant African Snail (Achatina fulica) exposed to the gastropod parasitic nematode Phasmarhabditis hermaphrodita. J. Invertebr. Pathol. 127, 122-126 (2015).

13. Williams, A. \& Rae, R. Cepaea nemoralis uses its shell as a defence mechanism to trap and kill parasitic nematodes. J. Mollus. Stud. 12, 1-2 (2016).

14. Rae, R. The gastropod shell has been co-opted to kill parasitic nematodes. Sci. Rep. 7, 4745. https://doi.org/10.1038/s41598-01704695-5 (2017).

15. Rae, R., 2018. Shell encapsulation of parasitic nematodes by Arianta arbustorum (Linnaeus, 1758) in the laboratory and in field collections. J. Molluscan Stud. 84, 92-95 (2018).

16. Cowlishaw, R. M., Andrus, P. \& Rae, R. An investigation into nematodes encapsulated in shells of wild, farmed and museum specimens of Cornu aspersum and Helix pomatia. J. Conchol. 43, 1-8 (2020).

17. Lowenstam, H. A. \& Weiner, S. On Biomineralization (Oxford University Press, Oxford, 1989).

18. Rae, R. G., Robertson, J. F. \& Wilson, M. J. Susceptibility and immune response of Deroceras reticulatum, Milax gagates and Limax pseudoflavus exposed to the slug parasitic nematode Phasmarhabditis hermaphrodita. J. Invertebr. Pathol. 97, 61-69 (2008).

19. Littlewood, D. T. J. \& Donovan, S. K. Fossil parasites: a case of identity. Geol. Today. 19, 136-142 (2003).

20. Poinar, G. O. Jr. The geological record of parasitic nematode evolution. Adv. Parasitol. 90, 53-92 (2015).

21. Garwood, R., Dunlop, J.A. \& Sutton, M.D. High-fidelity X-ray micro-tomography reconstruction of siderite-hosted Carboniferous arachnids. Biol. Lett. 5, 6 https://doi.org/10.1098/rsbl.2009.0464 (2009).

22. Inoue, S. \& Kondo, S. Structure pattern formation in ammonites and the unknown rear mantle structure. Sci. Rep. 6, 33689; https ://doi.org/10.1038/srep33689 (2016).

23. Shapiro, B. Ancient DNA. In Princeton Guide to Evolution (ed. Losos, J.) 475-481 (Princeton, Princeton University Press, 2013).

24. Slon, V. et al. The genome of the offspring of a Neanderthal mother and a Denisovan father. Nature 561, 113-116 (2018).

25. Swarts, K. et al. Genomic estimation of complex traits reveals ancient maize adaptation to temperate North America. Science 357, 512-515 (2017).

26. Spyrou, M. A. et al. Analysis of 3800-year-old Yersinia pestis genomes suggests Bronze Age origin for bubonic plague. Nat. Commun. 9, 2234. https://doi.org/10.1038/s41467-018-04550-9 (2018).

27. Loreille, O., Roumat, E., Verneau, O., Bouchet, F. \& Hänni, C. Ancient DNA from Ascaris: extraction amplification and sequences from eggs collected from coprolites. Int. J. Parasitol. 31, 1101-1106 (2001).

28. Søe, M. J., Nejsum, P., Fredensborg, B. L. \& Kapel, C. M. O. DNA typing of ancient parasite eggs from environmental samples identifies human and animal worm infections in Viking-age settlement. J. Parasitol. 101, 57-63 (2015). 
29. Lubell, D. Prehistoric edible land snails in the cicum-Mediterranean: the archaeological evidence. In Petits Animaux et Societes Humaines. Du Complement Alimentaire Aux Resources Utiliaires. XXIVe rencontres internationals d'archeologie et d'histoire d'Antibes (eds. Brugal, J-J \& Dess, J.) 77-98 (Editions APDCA, 2004).

30. Eamsobhana, P. Eosinophilic meningitis caused by Angiostrongylus cantonenses - a neglected disease with escalating importance. Trop. Biomed. 31, 569-578 (2014).

\section{Acknowledgements}

We are grateful to LJMU for use of equipment and facilities.

\section{Author contributions}

R.R. and P.F. conceived the experiment and wrote the manuscript. P.F. carried out experiment and conducted analysis.

\section{Competing interests}

The authors declare no competing interests.

\section{Additional information}

Supplementary Information The online version contains supplementary material available at https://doi. org/10.1038/s41598-021-82106-6.

Correspondence and requests for materials should be addressed to R.R.

Reprints and permissions information is available at www.nature.com/reprints.

Publisher's note Springer Nature remains neutral with regard to jurisdictional claims in published maps and institutional affiliations.

(c) (1) Open Access This article is licensed under a Creative Commons Attribution 4.0 International License, which permits use, sharing, adaptation, distribution and reproduction in any medium or format, as long as you give appropriate credit to the original author(s) and the source, provide a link to the Creative Commons licence, and indicate if changes were made. The images or other third party material in this article are included in the article's Creative Commons licence, unless indicated otherwise in a credit line to the material. If material is not included in the article's Creative Commons licence and your intended use is not permitted by statutory regulation or exceeds the permitted use, you will need to obtain permission directly from the copyright holder. To view a copy of this licence, visit http://creativecommons.org/licenses/by/4.0/.

(C) The Author(s) 2021 